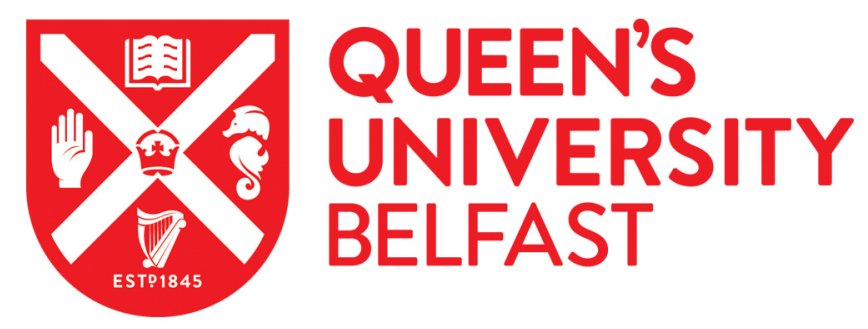

\title{
Borenium lonic Liquids as Alternative to BF3 in Polyalphaolefins (PAOs) Synthesis
}

Hogg, J. M., Ferrer-Ugalde, A., Coleman, F., \& Swadźba-Kwaśny, M. (2019). Borenium Ionic Liquids as Alternative to $\mathrm{BF}_{3}$ in Polyalphaolefins (PAOs) Synthesis. ACS Sustainable Chemistry and Engineering, 7(17), 15044-15052. https://doi.org/10.1021/acssuschemeng.9b03621

Published in:

ACS Sustainable Chemistry and Engineering

Document Version:

Peer reviewed version

Queen's University Belfast - Research Portal:

Link to publication record in Queen's University Belfast Research Portal

Publisher rights

Copyright 2019 ACS. This work is made available online in accordance with the publisher's policies. Please refer to any applicable terms of use of the publisher.

\section{General rights}

Copyright for the publications made accessible via the Queen's University Belfast Research Portal is retained by the author(s) and / or other copyright owners and it is a condition of accessing these publications that users recognise and abide by the legal requirements associated with these rights.

Take down policy

The Research Portal is Queen's institutional repository that provides access to Queen's research output. Every effort has been made to ensure that content in the Research Portal does not infringe any person's rights, or applicable UK laws. If you discover content in the Research Portal that you believe breaches copyright or violates any law, please contact openaccess@qub.ac.uk. 


\title{
Borenium ionic liquids as alternative to $\mathrm{BF}_{3}$ in
}

\section{polyalphaolefins (PAOs) synthesis}

\author{
James M. Hogg, ${ }^{a, b}$ Albert Ferrer-Ugalde ${ }^{a}$ Fergal Coleman ${ }^{a, c}$ Matgorzata Swadźba-Kwaśny ${ }^{a^{*}}$ \\ ${ }^{a}$ The QUILL Research Centre, School of Chemistry and Chemical Engineering, Queen's \\ University Belfast, Belfast, BT9 5AG, UK; m.swadzba-kwasny@qub.ac.uk \\ ${ }^{b}$ Recycling Technologies, Unit 2, Stirling Court, Stirling Road, Swindon, SN3 4TQ \\ ${ }^{c}$ Trifol Resources Ltd, Unit 1, Clonminam Business Park, Portlaoise, R32 P380, Ireland
}

KEYWORDS: Borenium, Lewis acids, ionic liquids, carbocationic oligomerization, 1-decene, polyalphaolefins (PAOs)

ABSTRACT: Lewis superacidic borenium ionic liquids of the general formula $\left[\mathrm{BCl}_{2}(\mathrm{~L})\right]\left[\mathrm{M}_{n} \mathrm{Cl}_{3 n+1}\right](\mathrm{L}=$ pyridine or picoline, $n=1$ or 2$)$ were used as catalysts for the oligomerization of 1-decene to polyalphaolefins (PAOs), as a safer alternative to the conventional $\mathrm{BF}_{3}$ catalyst, which is a toxic and corrosive gas. The catalytic activity of the borenium system could be tuned by modifying the ligand on the borenium cation, the chlorometallate anion and the reaction temperature. Following the optimization of the reaction conditions on small scale, the reaction was scaled up to $3 \mathrm{~L}$. Following fractional distillation of the crude product and blending, lubricant base oils matching market specifications (viscosity index, pour point) for PAO4 and 
PAO6 grades were obtained. Synthesised from inexpensive, off-the-shelf components, borenium ionic liquids are a new, cost-effective alternative to $\mathrm{BF}_{3}$, offering substantial gains in process safety and CAPEX savings. 


\section{Introduction}

Automotive lubricants are blends of a base oil and additives, which vary in proportion depending on the application. ${ }^{1}$ Hydrocarbon base oils are divided into four groups with differing physical and chemical properties. Synthetic polyalphaolefins (PAOs), which belong to Group IV, have superior physical properties compared to those produced from crude oil refining (Groups I-III). ${ }^{2}$ They have viscosity index (VI) above 120 units, which indicates a smaller change in viscosity with increasing temperature, a low pour point (PP) below $-40^{\circ} \mathrm{C}$, which makes them suitable for low temperature applications, and low Noack volatility, which contributes to better stability in higher applications. Finally, lower content of impurities and unsaturated hydrocarbons contributes to a higher oxidative stability of PAOs compared to Groups I-III base oils. ${ }^{2}$ PAOs are divided into classes based on their kinematic viscosity at $100{ }^{\circ} \mathrm{C}(\mathrm{Kv} 100)$, and are blended to fit within one of the several categories: $\mathrm{Kv}_{100}=2,4,6,8,10,40$ and $100 \mathrm{cSt}^{3}{ }^{3} \mathrm{PAO} 4$ and 6 are the most sought after as low-viscosity, high performance automotive lubricants. The PAO market is continuously growing, as the modern automotive market favors synthetic lubricants based on PAOs, which are instrumental in reducing wear and tear of engine parts, as well as improving fuel economy.

The molecular structure of PAOs (length and branching of hydrocarbon chains) determines the properties of the lubricant. In general, linear alkyl chains have favorably high VIs but also undesirably high PP, whereas highly branched hydrocarbons have low VI and PP. ${ }^{4-6}$ Commercial PAOs require very carefully balanced degree of branching, to attain sufficiently low pour point without compromising the temperature-dependent viscosity properties. These properties depend to a largest extent on the catalyst used in PAO production. 
The vast majority of PAOs are produced via the carbocationic oligomerization of 1-decene, using a strong Lewis acid catalyst. The Lewis acid is either promoted with a protic additive (e.g. an alcohol) or interacts with adventitious water, to generate Brønsted superacidic protons, capable of protonating 1-decene and initiating the oligomerization reaction. ${ }^{7}$ Low viscosity lubricants (PAO4 and 6) contain predominantly the trimer (C30), tetramer (C40) and pentamers (C50) of 1-decene, and are industrially produced through the $\mathrm{BF}_{3} / n \mathrm{BuOH}$-catalyzed oligomerization, which gives only a small proportion of the dimer and little to no heavy oligomers in the crude product. ${ }^{8-10}$ In contrast, conventional catalysts based on $\mathrm{AlCl}_{3}$, or on metallocenes, deliver very high viscosity lubricants: ${ }^{11}$ aluminium yielding branched chains of high molecular weight, and metallocenes linear oligomers with high pour points. ${ }^{8}$

In the synthesis of PAO4 and 6, the fundamental drawback is that $\mathrm{BF}_{3}$ is a toxic gas, which hydrolyses to release HF and subsequently fluoroboric acid. This poses significant operational hazard and - in the industrial setting - incurs very high CAPEX overhead to ensure the plant safety. The challenge lies in identifying a catalyst that would produce base oils matching exactly the same specifications as those produced with $\mathrm{BF}_{3}$ (aligned with the needs of the automotive industry) but using a safer and economically viable catalyst. $\mathrm{BF}_{3}$ promoted with protic additives is the only commercially used catalyst for low-viscosity PAOs, whereas Al-based catalysts $\left(\mathrm{AlCl}_{3}, \mathrm{EtAlCl}_{2}\right.$, chloroaluminate ionic liquids) promoted with water or alcohols typically give heavier, high viscosity products. ${ }^{8}$ With careful fine-tuning of conditions, medium-visocisty polymers can be accessed. ${ }^{12}$ Metallocene catalysts, sometimes with an aluminium co-catalysts, produce very high viscosity oligomers/polymers. ${ }^{8,13}$ Brønsted acids, in contrast, yield very light products. ${ }^{14}$

Chloroaluminate ionic liquids, based on an organic cation and a chloroaluminate anion, $\left[\mathrm{Al}_{2} \mathrm{Cl}_{7}\right]^{-15}$ which feature prominently in the patent literature as promoting the production of heavy 
oligomers, ${ }^{16-18}$ inspired our group's search for Lewis acidic ionic liquids yielding low-viscosity PAOs. Lewis acidic chlorogallate ionic liquids (exemplified in Scheme 1, A) gave favorable products distribution and good yields (up to $>90 \%$ ), but were much too costly for commercial use. ${ }^{19}$ Liquid coordination complexes (LCCs) based on aluminium(III) chloride (Scheme 1, B) ${ }^{20}$ delivered surprisingly low molecular weight oligomers with low viscosities for Al-centered Lewis acids, and were more cost effective than conventional chloroaluminate ionic liquid, having dispensed with an organic cation. ${ }^{21}$ However, they gave lower yields (about 70-85\%) and lower selectivities to $\mathrm{PAO} 4$ and 6 than that of $\mathrm{BF}_{3}$. In this work we introduce a process catalyzed by borenium ionic liquids (exemplified in Scheme 1, C) which are the first reported ionic liquid systems with Lewis acidic cations. ${ }^{22}$<smiles></smiles>

A

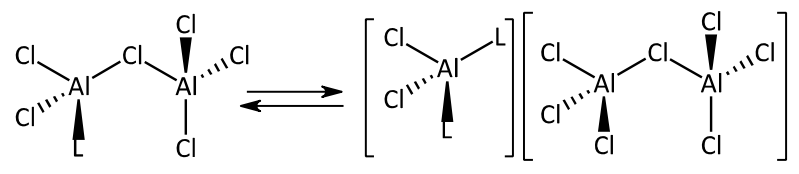

B

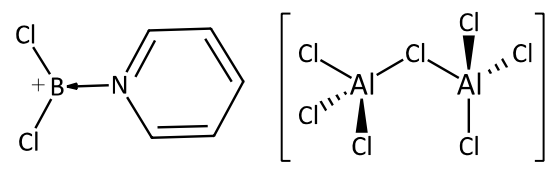

C

Scheme 1. Examples of structures of: chlorogallate ionic liquids (A), liquid coordination complex, where L = urea, trioctylphosphine oxide, trioctylphosphine etc. $(B)$ and borenium ionic liquids $(C)$.

Borenium cations are recognized for their high Lewis acidity, ${ }^{23,24}$ and the systems used here are inexpensive, extremely active,$^{25}$ and give higher selectivities and conversions than any LCCs reported to date. 


\section{Experimental}

\section{Materials and methods}

All experiments were carried out under inert atmosphere using a glovebox or standard Schlenk techniques. All pyridine ligands were purchased from Sigma Aldrich ( $>98 \%$ ), purified by distillation and stored under argon over dried $3 \AA$ molecular sieves. Boron trichloride was purchased as a $1 \mathrm{M}$ solution in heptanes from Sigma Aldrich and used as received. For small-scale experiments, $\mathrm{AlCl}_{3}(99.999 \%)$ and $\mathrm{GaCl}_{3}(99.999 \%)$ were purchased from Alfa Aesar in sealed ampules which were transferred to the glovebox (MBraun labmaster dp, $<0.3$ ppm of $\mathrm{H}_{2} \mathrm{O}$ and $\mathrm{O}_{2}$ ). The materials were used as received. For large scale reaction $\mathrm{AlCl}_{3}(98 \%)$ was purchased from Sigma Aldrich and was doubly sublimed before use, following a literature procedure. ${ }^{21,26}$

\section{Syntheses of borenium ionic liquids}

Borenium ionic liquids were synthesized according to literature procedures. ${ }^{22} \mathrm{BCl}_{3}$ in heptane $\left(5 \mathrm{~cm}^{3}, 5 \mathrm{mmol}\right)$ in dichloromethane $\left(20 \mathrm{~cm}^{3}\right)$ was cooled to $-78^{\circ} \mathrm{C}$ before dropwise addition of a dry base: pyridine $(0.36 \mathrm{~g}, 4.5 \mathrm{mmol})$ or picoline $(0.42 \mathrm{~g} 4.5 \mathrm{mmol})$. The resulting mixture was stirred for $1 \mathrm{~h}$ before the removal of the volatiles under reduced pressure. Adducts, that formed quantitatively as white powders, were dried $\left(60^{\circ} \mathrm{C}, 10^{-2}\right.$ bar, overnight $)$ and transferred to the glovebox.

In the glovebox, an adduct $(4.5 \mathrm{mmol})$ was placed in a vial equipped with a stirring bar, and $\mathrm{MCl}_{3}$ ( $\mathrm{M}=\mathrm{Al}, \mathrm{Ga}, 4.5 \mathrm{mmol}$ or $9 \mathrm{mmol})$ was added slowly, with little heat evolved. The mixture was then heated and stirred $\left(50^{\circ} \mathrm{C}, c a .1 \mathrm{~h}\right)$, until a homogenous liquid was obtained. All adducts and ionic liquids were analyzed by ${ }^{1} \mathrm{H},{ }^{11} \mathrm{~B}$ and, where appropriate, ${ }^{27} \mathrm{Al}$ NMR spectroscopy (Bruker 
AvanceIII $400 \mathrm{MHz}$ spectrometer). Adducts were measured as solutions in $\mathrm{CDCl}_{3}$, whereas ionic liquids were studied neat, with $d_{6}$-dmso capillary as an external lock. Expanded experimental procedures and full NMR spectroscopic characterization is shown in the SI (Figures S1 - S30).

\section{Small-scale oligomerization of 1-decene}

Oligomerization reactions were carried out according to the earlier-established procedure. ${ }^{21}$ On the small scale, experiments were carried out in a battery of eight glass computer-controlled H.E.L. reactors $\left(120 \mathrm{~cm}^{3}\right)$ designed for high corrosion resistance, and equipped with efficient temperature control (cooling/heating) system. The reactor vessels and stirrer propellers were dried overnight in an oven $\left(>100{ }^{\circ} \mathrm{C}\right)$, and then cooled in a desiccator. The remaining parts were dried with a heat gun (ca. $5 \mathrm{~min})$ immediately prior to use, and the reactors were assembled. 1-Decene $\left(40 \mathrm{~cm}^{3}\right)$ was poured into the reactors and stirred vigorously $(600 \mathrm{rpm})$ at the reaction temperature $(60-130$ $\left.{ }^{\circ} \mathrm{C}\right)$, whilst the reactors were purged with argon. The borenium ionic liquid $(0.62 \mathrm{mmol}, \mathrm{ca} .1 \mathrm{wt}$ \%) was loaded into a gas-tight syringe in the glovebox, transported to reactors in a syringe with tip protected from atmospheric moisture, and added to the 1-decene. The catalyst addition was performed as quick drop-wise addition, over $c a .10 \mathrm{~s}$, resulting in a strong exotherm. After certain time (1-1.5 h), the reaction was quenched with water. The organic phase was dried over $\mathrm{MgSO}_{4}$, filtered, and analyzed by SimDist GC.

\section{Scaled-up oligomerization of 1-decene}

Reactions were carried out in a computer-controlled glass H.E.L. reactor (5 L). The fully assembled reactor was dried $\left(60{ }^{\circ} \mathrm{C}, 30 \mathrm{~min}, 10^{-2} \mathrm{mbar}\right)$ prior to the reaction, and then 1 -decene (3 kg, $21.4 \mathrm{~mol}$ ) was added under positive pressure of argon; the reactor was then purged with argon $(10 \mathrm{~min})$. Subsequently, vigorously stirred $(600 \mathrm{rpm}) 1$-decene was heated to the reaction 
temperature $\left(60-100{ }^{\circ} \mathrm{C}\right)$. The borenium ionic liquid $(5.75-27.75 \mathrm{~g}, 12-60 \mathrm{mmol})$ was loaded into a dry gas-tight syringe, following the procedure analogous to that for small-scale oligomerization, albeit the syringe was placed in a syringe pump. The catalyst was subsequently added using a syringe pump, at a pace designed to prevent thermal runaway $\left(0.2 \mathrm{~cm}^{3} \mathrm{~min}^{-1}\right)$. After a given reaction time, the stirring was stopped, and the system was allowed to cool to ambient temperature. The reaction mixture was washed with deionized water $\left(3 \times 10^{3} \mathrm{~cm}^{3}\right)$, and each time the reactor content was heated to $95{ }^{\circ} \mathrm{C}$, in order to ensure dissolution of the boric acid produced by hydrolysis of the catalyst. Each wash, the bottom (aqueous) layer was removed through the tap located at the bottom of the reactor vessel. The product was dried over $\mathrm{MgSO}_{4}$ and filtered through a large sintered funnel.

\section{Simulated distillation gas chromatography (SimDist GC)}

Samples for SimDist GC analysis were dissolved in toluene $\left(100 \mathrm{mg} \mathrm{cm}^{-3}\right)$, dried over magnesium sulfate, filtered and analyzed according to ASTM D6352. ${ }^{27}$ The analysis were carried out using Agilent $6890 \mathrm{~N}$ GC, equipped with an FID detector and a high-performance HT PTV (high temperature programmable temperature vaporizing) inlet with optimized design for SIMDIST applications. Column: Agilent J\&W DB-HT 5M SimDist Column. Reproducibility of the results was limited by the reproducibility of the reaction outcome, rather than the error of the analytical method, as already reported. ${ }^{21}$ Error associated with each product fraction is shown in Table 1.

Table 1. Error in reproducibly producing each fraction of oligomers. ${ }^{21}$

\begin{tabular}{cccccccc}
\hline & Conversion (\%) & $\mathbf{C}_{\mathbf{2 0}}(\mathbf{\%})$ & $\mathrm{C}_{\mathbf{3 0}} \mathbf{( \% )}$ & $\mathrm{C}_{\mathbf{4 0}} \mathbf{( \% )}$ & $\mathrm{C}_{\mathbf{5 0}} \mathbf{( \% )}$ & $\mathrm{C}_{\mathbf{6 0}} \mathbf{( \% )}$ & $\mathbf{C}_{\mathbf{7 0}+}(\mathbf{\%})$ \\
\hline Error & \pm 3 & \pm 4 & \pm 3 & \pm 2 & \pm 2 & \pm 1 & \pm 1 \\
\hline
\end{tabular}

\section{Distillation}


Fractionated distillation was carried out in a computer-controlled DistriLab D5236 Crude Oil Distillation System, equipped with a $6 \cdot 10^{3} \mathrm{~cm}^{3}$ boiling flask, according to ASTM D5236. ${ }^{28}$ In a typical procedure, the distillation rig was dried prior to use (1 $\mathrm{mmHg}, 30 \mathrm{~min})$. A sample (2 $4 \cdot 10^{3} \mathrm{~cm}^{3}$ ) was dried over $\mathrm{MgSO}_{4}$, filtered and loaded into the boiling flask. Unreacted decene was distilled first (10 $\mathrm{mmHg})$, then the mixture was cooled and the decene fraction was removed from the distillation rig. Subsequently, the dimer $\left(\mathrm{C}_{20}\right)$ fraction was distilled $(0.1 \mathrm{mmHg}$, vigorous stirring). Then, the distillation rig was cleaned by distilling toluene, in order to prevent contamination of subsequent fractions. The trimer $\left(\mathrm{C}_{30}\right)$ was fractionally distilled $(0.1 \mathrm{mmHg})$ with the $\mathrm{C}_{30}$ and distillation residue being blended to give PAO 4 and 6 samples. A minimum of $0.4 \cdot 10^{3} \mathrm{~cm}^{3}$ (the heaviest fraction) was left in the boiling flask as a residue. All fractions and the residue were analyzed using SimDist GC. After blending appropriate proportions of $\mathrm{C}_{30}$, heavier fractions and the residue, the pour point, $\mathrm{Kv}_{40}$ and $\mathrm{Kv}_{100}$ values were measured, and VI was calculated.

\section{Physical properties tests}

Pour point was measured according to ASTM D97-11. ${ }^{29}$ The pour point cryostat (Stanhope-Seta, Model 93531-7) was validated against a standard gas oil sample (99851-0) according to ASTM method (pour point $-15^{\circ} \mathrm{C}$, cloud point $-4{ }^{\circ} \mathrm{C}$ ). Each sample was placed in a glass vessel fitted with a low temperature thermometer and held in a bath heated to $45^{\circ} \mathrm{C}$ until the temperature was reached, before transferring to a constant temperature bath held at $24{ }^{\circ} \mathrm{C}$. Once cooled to $27{ }^{\circ} \mathrm{C}$, it was transferred to a bath at $0{ }^{\circ} \mathrm{C}$, followed by consecutive baths held at $-18{ }^{\circ} \mathrm{C},-33^{\circ} \mathrm{C},-51{ }^{\circ} \mathrm{C}$ and $-69^{\circ} \mathrm{C}$ (the last temperature was achieved using a dry ice bath). The samples were removed from the baths and tested for flow by tilting the glass vessel at every $3{ }^{\circ} \mathrm{C}$ temperature decrease. 
Kinematic viscosities $(\mathrm{Kv})$ were measured according to ASTM D445-11a. ${ }^{30}$ The measurements were performed at 40 and $100{ }^{\circ} \mathrm{C}$ using the appropriate Cannon-Fenske kinematic viscosity glassware and a precisely-controlled heating bath. Kv was found by timing the gravitational flow of the sample through a capillary.

Viscosity index (VI) was calculated from $\mathrm{Kv}$ data, according to eq (1). L and $\mathrm{H}$ are constants based on Kv100, tabularized in ASTM $2270 .{ }^{31}$

$$
\mathrm{VI}=100(\mathrm{~L}-\mathrm{Kv} 40)(\mathrm{L}-\mathrm{H})^{-1}
$$

\section{Hydrogenation}

Hydrogenation reactions were carried out in a $250 \mathrm{~cm}^{3}$ stainless steel Paar reactor. Crude PAO product $\left(100 \mathrm{~cm}^{3}\right)$ was loaded into the reactor with $0.5 \mathrm{~g}$ of $\mathrm{Pd} / \mathrm{C}$ and the reactor was sealed, purged with positive pressure of argon, and then pressurized to 40 bar with $\mathrm{H}_{2}$. Hydrogenation was carried out $\left(100{ }^{\circ} \mathrm{C}, 600 \mathrm{rpm}, 2 \mathrm{~h}\right)$, and then the mixture was filtered to yield hydrogenated PAO. Analysis by ${ }^{1} \mathrm{H}$ NMR showed no aromatic or olefinic peaks.

\section{Results and Discussion}

\section{Syntheses of borenium ionic liquids}

All tetracoordinate boron adducts, $\left[\mathrm{BCl}_{3} \mathrm{~L}\right]$, formed readily as white powders, without observable side reactions, as reported in the literature. ${ }^{22}$ The complexes $(\mathrm{L}=$ py, 3pic or 4pic) were all found to be stable in air and could be recrystallized from dry DCM/hexane, yielding ${ }^{1} \mathrm{H}$ and ${ }^{11} \mathrm{~B}$ NMR spectra in agreement with the literature. ${ }^{22}$ 
An exception was noted for the reaction of 2-picoline and $\mathrm{BCl}_{3}$, whereby the white powder that formed, dissolved in $\mathrm{CDCl}_{3}$, gave ${ }^{11} \mathrm{~B}$ NMR spectrum showing two signals at 8.65 and $7.21 \mathrm{ppm}$, in 3:1 ratio, and ${ }^{1} \mathrm{H}$ NMR spectroscopy showed two ligand environments, at 1:1 ratio. Attempts to purify by recrystallization in air resulted in decomposition of the sample. Variable temperature ${ }^{1} \mathrm{H}$ NMR spectroscopy $\left(25-40^{\circ} \mathrm{C}\right)$ showed no significant variation in the ratio of these peaks. It can be reasonably assumed that the methyl group in the alpha position with respect to the nitrogen atom induces steric hindrance and weakens the B-N bond, which is known to encourage disproportionation of the adduct (Equation 2) in chemistry of boron complexes. ${ }^{32}$ As such, this equilibrium observed via NMR spectroscopy is an inherent property of the compound, rather than impurity.

$$
2\left[\mathrm{BCl}_{3}(2 \mathrm{pic})\right] \rightleftarrows\left[\mathrm{BCl}_{2}(2 \mathrm{pic})_{2}\right]\left[\mathrm{BCl}_{4}\right]
$$

Most importantly in the context of this work, the reaction of $\left[\mathrm{BCl}_{3}(2 \mathrm{pic})\right]$ with two moles of $\mathrm{AlCl}_{3}$ resulted in the reaction product analogous with other systems. The ${ }^{1} \mathrm{H}$ NMR spectrum featured a single set of signals corresponding to the 2-picoline ligand, shifted downfield indicating loss of electron density from the aromatic ring. The ${ }^{11} \mathrm{~B}$ NMR spectrum features a single broad peak at $\delta$ ${ }^{11} \mathrm{~B}=45.0 \mathrm{ppm}$, indicative of the borenium cation, $\left[\mathrm{BCl}_{2}(2 \mathrm{pic})\right]^{+}$, as well as a small peak at $\delta{ }^{11} \mathrm{~B}$ $=7.6 \mathrm{ppm}(<1 \%$ area $)$, potentially a hydrolysis product caused by adventitious water. The corresponding ${ }^{27} \mathrm{Al}$ NMR spectra shows a single broad peak at $\delta{ }^{27} \mathrm{Al}=104 \mathrm{ppm}$, attributable to $\left[\mathrm{Al}_{2} \mathrm{Cl}_{7}\right]^{-}$. All this points to the formation of the borenium ionic liquid.

The addition of 1 or 2 equivalents of $\mathrm{AlCl}_{3}$ or $\mathrm{GaCl}_{3}$ to the $\left[\mathrm{BCl}_{3} \mathrm{~L}\right]$ adducts afforded ionic liquids: either room-temperature liquids, or low-melting solids (Table 2), in agreement with the literature. ${ }^{22}$ 
Table 2. Physical state of borenium ionic liquids synthesized here, at ambient conditions, as a function of cation-anion combination.

\begin{tabular}{|c|c|c|c|c|}
\hline & {$\left[\mathrm{BCl}_{2}(\mathrm{py})\right]^{+}$} & {$\left[\mathrm{BCl}_{2}(2 \mathrm{pic})\right]^{+}$} & {$\left[\mathrm{BCl}_{2} \text { (3pic) }\right]^{+}$} & {$\left[\mathrm{BCl}_{2}(4 \text { pic })\right]^{+}$} \\
\hline$\left[\mathrm{AlCl}_{4}\right]^{-}$ & Solid/Gel & Liquid & Liquid & Solid/Gel \\
\hline$\left[\mathrm{Al}_{2} \mathrm{Cl}_{7}\right]^{-}$ & Liquid & Liquid & Liquid & Liquid \\
\hline$\left[\mathrm{GaCl}_{4}\right]^{-}$ & Solid/Gel & Liquid & Liquid & Solid/Gel \\
\hline$\left[\mathrm{Ga}_{2} \mathrm{Cl}_{7}\right]^{-}$ & Liquid & Liquid & Liquid & Liquid \\
\hline
\end{tabular}

Each ionic liquid listed in Table 2 comprises two main components: a Lewis acidic borocation, $\left[\mathrm{BCl}_{2} \mathrm{~L}\right]^{+}$, combined with either a Lewis neutral anion, $\left[\mathrm{MCl}_{4}\right]^{-}$, or a Lewis acidic one, $\left[\mathrm{M}_{2} \mathrm{Cl}_{7}\right]^{-}$. Since the $\left[\mathrm{MCl}_{4}\right]^{-}$anion is more coordinating, borenium cations in the $\left[\mathrm{BCl}_{2} \mathrm{~L}\right]\left[\mathrm{MCl}_{4}\right]$ systems are less Lewis acidic compared to the same cations combined with $\left[\mathrm{M}_{2} \mathrm{Cl}_{7}\right]^{-}$, which manifests itself through lower AN values (where AN is Gutmann acceptor number, a quantitative measure of Lewis acidity) and more upfield ${ }^{11} \mathrm{~B}$ NMR chemical shifts. ${ }^{22}$ In contrast, $\left[\mathrm{BCl}_{2} \mathrm{~L}\right]\left[\mathrm{M}_{2} \mathrm{Cl}_{7}\right]$ ionic liquids feature two strongly Lewis acidic centres: a Lewis superacidic cation $(\mathrm{AN}>150)$ and highly Lewis acidic anion (AN of $c a .96){ }^{19,33}$

In terms of catalytic reactivity, it has long been established that ionic liquids with organic (spectator) cations and Lewis neutral anions, $\left[\mathrm{MCl}_{4}\right]^{-}(\mathrm{M}=\mathrm{Al}$ or $\mathrm{Ga})$, are catalytically inactive, whereas ionic liquids with Lewis acidic anions, $\left[\mathrm{M}_{2} \mathrm{Cl}_{7}\right]^{-}$, are recognized as strong Lewis acids. ${ }^{15,34}$ The same is true for liquid coordination complexes based on $\mathrm{Al}$ or $\mathrm{Ga}$, which were found catalytically inactive when containing only mononuclear complexes, $\left[\mathrm{AlCl}_{2} \mathrm{~L}_{2}\right]\left[\mathrm{AlCl}_{4}\right]$, but displayed high catalytic activity with dinuclear complexes, $\left[\mathrm{AlCl}_{2} \mathrm{~L}_{2}\right]\left[\mathrm{Al}_{2} \mathrm{Cl}_{7}\right]$ (Scheme 1, B). ${ }^{21,35}$ Finally, in our earlier work on borenium ionic liquids as catalysts for Diels-Alder reaction, we found $\left[\mathrm{C}_{2} \mathrm{mim}\right]\left[\mathrm{AlCl}_{4}\right]$ catalytically inactive, in contrast to borenium ionic liquids with this anion, that were active catalysts. ${ }^{25}$ This leads to the general conclusion that ionic liquids of a general formula $\left[\mathrm{BCl}_{2} \mathrm{~L}\right]\left[\mathrm{MCl}_{4}\right]$ are catalytically active due to the cation, and those with formula $[\mathrm{BCl} 2 \mathrm{~L}]\left[\mathrm{M}_{2} \mathrm{Cl}_{7}\right]$ have two Lewis acidic centres, in the cation and the anion. 
Adding complexity is the fact that carbocationic oligomerisation of higher olefins with Group 13 halides is initiated by a Lewis/Brønsted acid system, rather than by a direct interaction of a Lewis acid with the double bond. ${ }^{7}$ Upon the addition of a Lewis acidic ionic liquid to the reaction mixture, it interacts with adventitious water and generates Brønsted superacidic protons in an exothermic reaction. These protons then protonate 1-decene (initiation). Subsequently, carbocationic oligomerization occurs, with the propagating carbocation accompanied by anions present in the system. In parallel, chain isomerization takes place. The activity of both Brønsted acidic proton and propagating carbocation is considered to be more dependent on the coordinating ability of the strongest base in the system (that is, the anions), than on the initial strength of the Lewis acid. Finally, termination occurs, simultaneously through a number of routes. Therefore, the overall outcome is not dependent on a single factor, such as Lewis acidity, but on the combination of a number of variables, and is therefore difficult to predict. ${ }^{7}$

\section{Small-scale oligomerization of 1-decene}

From very preliminary experiments it has been known that borenium ionic liquids were capable of oligomerizing 1-decane to generate dimers, trimers, tetramers and some heavier oligomers. ${ }^{36}$ From the process perspective, it was important to maximize conversion (ideally reaching over $90 \%$ ), in order to limit recycle of the decane fraction, and to minimize the yield of low-value $\mathrm{C}_{20}$ fraction. Yields of $\mathrm{C}_{30}$ and $\mathrm{C}_{40}$ fractions were to be maximized, as most desirable for PAO4 and 6 .

Small-scale experiments, carried out in a batch of $120 \mathrm{~cm}^{3}$ reactors, were conducted to elucidate the influence of the anion, the cation, and the reaction conditions on conversion and products distribution. 
Influence of the anion. A set of four ionic liquids, of the general formula $\left[\mathrm{BCl}_{2}(3 \mathrm{pic})\right]\left[\mathrm{M}_{n} \mathrm{Cl}_{3 n+1}\right]$ $(\mathrm{M}=\mathrm{Al}$ or $\mathrm{Ga}, n=1$ or 2$)$, were tested under fixed reaction conditions $(0.62 \mathrm{mmol}$ of catalyst per $40 \mathrm{~cm}^{3}$ of 1-decene, $1 \mathrm{~h}, 100^{\circ} \mathrm{C}$ ). 3-Picoline was selected as the ligand, given that it produced liquid samples for all four compositions (viz. Table 2). Conversions and product distributions are tabularized in Table 3; to aid interpretation, product distributions are also visualized using a stacked bar graph (Figure 1). 
Table 3 Conversions, product distribution and exotherms in $\left[\mathrm{BCl}_{2}(3\right.$ pic) $]\left[\mathrm{M}_{n} \mathrm{Cl}_{3 n+1}\right]$ catalyzed oligomerization, $0.62 \mathrm{mmol}$ of catalyst, $1 \mathrm{~h}, 100^{\circ} \mathrm{C}, \mathrm{M}=\mathrm{Al}$ or $\mathrm{Ga}, n=1$ or 2, compared to Lewis acidity of the borocation, expressed as AN (from ref 18).

\begin{tabular}{|c|c|c|c|c|c|c|c|c|c|c|}
\hline Anion & $\begin{array}{c}\text { Conversion } \\
( \pm 3 \%)\end{array}$ & $\begin{array}{l}C_{20} \\
( \pm 4 \\
\%)\end{array}$ & $\begin{array}{l}C_{30} \\
( \pm 3 \\
\%)\end{array}$ & $\begin{array}{l}C_{40} \\
( \pm 2 \\
\%)\end{array}$ & $\begin{array}{l}C_{50} \\
( \pm 2 \\
\%)\end{array}$ & $\begin{array}{l}C_{60} \\
( \pm 1 \\
\%)\end{array}$ & $\begin{array}{l}\mathbf{C}_{70+} \\
( \pm 1 \\
\%)\end{array}$ & $\begin{array}{c}\text { Exotherm } \\
\left({ }^{\circ} \mathrm{C}\right)\end{array}$ & $\mathbf{A \mathbf { N } ^ { 2 2 }}$ & $\begin{array}{l}\delta^{11} \mathbf{B}^{22} \\
\text { (ppm) }\end{array}$ \\
\hline$\overline{\left[\mathrm{AICl}_{4}\right]^{-}}$ & 82 & 28 & 35 & 17 & 9 & 5 & 7 & 20 & 124 & 31 \\
\hline$\left[\mathbf{A l}_{2} \mathbf{C l}_{7}\right]^{-}$ & 81 & 32 & 33 & 17 & 9 & 4 & 6 & 80 & 170 & 45 \\
\hline$\left[\mathrm{GaCl}_{4}\right]^{-}$ & 53 & 49 & 29 & 10 & 5 & 4 & 4 & 8 & 121 & 26 \\
\hline$\left[\mathrm{Ga}_{2} \mathrm{Cl}_{7}\right]^{-}$ & 77 & 43 & 35 & 13 & 5 & 2 & 3 & 55 & 135 & 44 \\
\hline
\end{tabular}

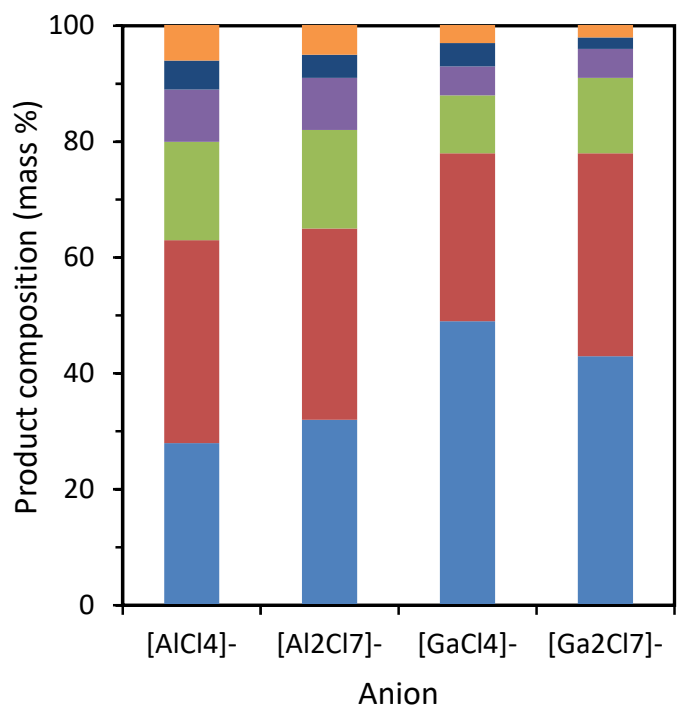

Figure 1: Product distribution from $\left[\mathrm{BCl}_{2}(3 \mathrm{pic})\right]\left[\mathrm{M}_{n} \mathrm{Cl}_{3 n+1}\right\}$ catalyzed oligomerization, $0.62 \mathrm{mmol}$ of catalyst, $1 \mathrm{~h}, 100^{\circ} \mathrm{C}, \mathrm{M}=\mathrm{Al}$ or $G a, n=1$ or 2 (blue $=C_{20}$, red $=C_{30}$, green $=C_{40}$, purple $=C_{50}$, navy $=C_{60}$, orange $\left.=C_{70^{+}}\right)$

The exotherm generated by the interaction of Lewis acidic ionic liquids with adventitious water to generate Brønsted superacidic protons, was to a certain degree corresponding to both reported measures of Lewis acidity of borenium cations: AN values and ${ }^{11} \mathrm{~B}$ NMR chemical shift (Table 3 ). However, Lewis acidity did not have a direct influence either on conversion, or selectivity to the $\mathrm{C}_{30}-\mathrm{C}_{50}$ fractions (desired products). Both chloroaluminate anions gave virtually the same performance, with $c a .81 \%$ conversion and $c a .30 \%$ of dimer $\left(\mathrm{C}_{20}\right.$, which is too light for PAO4 or PAO6 production). Chlorogallate systems had overall worse performance, with $\left[\mathrm{BCl}_{2}(3 \mathrm{pic})\right]\left[\mathrm{Ga}_{2} \mathrm{Cl}_{7}\right]$ giving lower conversion (77\%) and more $\mathrm{C}_{20}(43 \%)$ than either of the 
chloroaluminate ionic liquids, and even poorer performance when using $\left[\mathrm{BCl}_{2}(3 \mathrm{pic})\right]\left[\mathrm{GaCl}_{4}\right]$, with $53 \%$ conversion and $49 \%$ of $\mathrm{C}_{20}$. In conclusion, borenium chloroaluminate ionic liquids perform better than chlorogallate ones. From preliminary data, there was little difference between the performance of $\left[\mathrm{BCl}_{2}(3\right.$ pic) $\left.)\right]\left[\mathrm{AlCl}_{4}\right]$ and $\left[\mathrm{BCl}_{2}(3\right.$ pic $\left.)\right]\left[\mathrm{Al}_{2} \mathrm{Cl}_{7}\right]$.

Influence of the cation. Ionic liquids with a variety of pyridine ligands (L) on the borenium cation, $\left[\mathrm{BCl}_{2} \mathrm{~L}\right]^{+}$, combined with either chloroaluminate or chlorogallate anions, were screened (viz. Table 4 and Figure 2). Pyridine ligands were chosen because they are inexpensive (therefore present an industrially-viable option) and are already known to form borenium ionic liquids. ${ }^{22}$ In order to have all catalysts in the liquid form at ambient conditions, only $\left[\mathrm{M}_{2} \mathrm{Cl}_{7}\right]^{-}$anions were included in the screening.

Table 4: Conversion and product distribution achieved in $\left[\mathrm{BCl}_{2} \mathrm{~L}\right]\left[\mathrm{M}_{2} \mathrm{Cl}\right]$ catalyzed oligomerization, $0.62 \mathrm{mmol}, 1 \mathrm{~h}, 100^{\circ} \mathrm{C}$.

\begin{tabular}{|c|c|c|c|c|c|c|c|}
\hline Ligand & $\begin{array}{c}\text { Conversion } \\
( \pm 3 \%) \\
\end{array}$ & $\begin{array}{c}\mathrm{C}_{20} \\
( \pm 4 \%) \\
\end{array}$ & $\begin{array}{c}\mathrm{C}_{30} \\
( \pm 3 \%) \\
\end{array}$ & $\begin{array}{c}\mathrm{C}_{40} \\
( \pm 2 \%) \\
\end{array}$ & $\begin{array}{c}C_{50} \\
( \pm 2 \%) \\
\end{array}$ & $\begin{array}{c}\mathrm{C}_{60} \\
( \pm 1 \%)\end{array}$ & $\begin{array}{c}\mathrm{C}_{70+} \\
( \pm \mathbf{1 \%})\end{array}$ \\
\hline \multicolumn{8}{|l|}{$\mathbf{M}=\mathbf{A l}$} \\
\hline py & 85 & 29 & 32 & 19 & 11 & 5 & 4 \\
\hline 2 pic & 76 & 31 & 34 & 18 & 9 & 4 & 5 \\
\hline 3pic & 81 & 32 & 33 & 17 & 9 & 4 & 6 \\
\hline 4pic & 86 & 32 & 33 & 18 & 9 & 4 & 4 \\
\hline \multicolumn{8}{|l|}{$\mathbf{M}=\mathbf{G a}$} \\
\hline py & 84 & 41 & 34 & 14 & 5 & 2 & 4 \\
\hline 2 pic & 77 & 41 & 34 & 14 & 6 & 2 & 4 \\
\hline 3pic & 84 & 43 & 35 & 13 & 5 & 2 & 3 \\
\hline 4pic & 85 & 36 & 31 & 14 & 7 & 4 & 9 \\
\hline
\end{tabular}



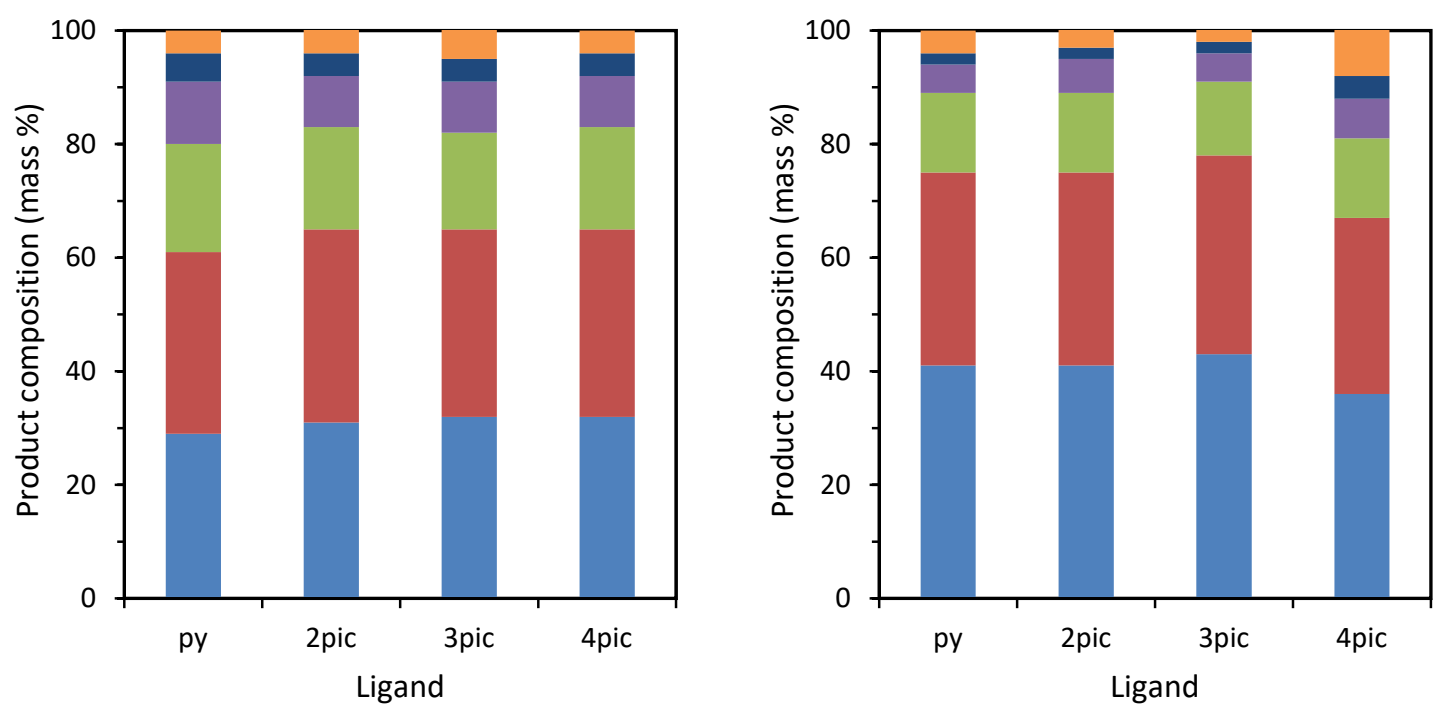

Figure 2: Product distribution from $\left[\mathrm{BCl}_{2}(\mathrm{~L})\right]\left[\mathrm{M}_{2} \mathrm{Cl} 7\right]$ catalyzed oligomerization, $0.62 \mathrm{mmol}$ of catalyst, $1 \mathrm{~h}, 100{ }^{\circ} \mathrm{C},\left(\mathrm{blue}=\mathrm{C}_{20}\right.$, red $=C_{30}$, green $=C_{40}$, purple $=C_{50}$, navy $=C_{60}$, orange $\left.=C_{70+}\right) . M=A l(l e f t)$ or Ga $($ right $)$.

For the same cation, conversions achieved with $\left[\mathrm{Al}_{2} \mathrm{Cl}_{7}\right]^{-}$and $\left[\mathrm{Ga}_{2} \mathrm{Cl}_{7}\right]^{-}$anion were nearly identical, but ionic liquids with $\left[\mathrm{Ga}_{2} \mathrm{Cl}_{7}\right]^{-}$produced shorter chains (more $\mathrm{C} 20$, less of the desired $\mathrm{C} 30-\mathrm{C} 50$ fraction and less heavies), indicating a greater rate of chain transfer with respect to propagation for the chlorogallate systems. This is in keeping with the anion influence screening (Table 2).

The presence and the position of the methyl group on the pyridine ligand had little effect upon the distribution of oligomers, discrepancies remaining within the error bars. However, conversion was consistently slightly lower for the $\left[\mathrm{BCl}_{2}(2 \mathrm{pic})\right]^{+}$cation, when compared to other ligands. In contrast to other ligands used in this study, the methyl group in the 2-position with respect to the nitrogen is a source of steric hindrance, which may weaken the B-N bond and affect catalytic activity, but more mechanistic insight would be required to understand how this would translate to lowering the conversion. 
Influence of the reaction temperature and catalyst loading. It is well-known that in the carbocationic polymerization of olefins, increase in reaction temperature results in decreased molecular weight of products (shorter chains are favored because the rate of termination processes is enhanced compared to propagation). ${ }^{7}$ This trend has been observed in our earlier work using liquid coordination complexes (LCCs) as catalysts for the oligomerization of 1-decene. ${ }^{21}$ The aim of this screening was to estimate the magnitude of this effect, and to study the influence of reaction temperature on conversion.

Firstly, a single catalyst, $\left[\mathrm{BCl}_{2}(2 \mathrm{pic})\right]\left[\mathrm{Al}_{2} \mathrm{Cl}_{7}\right]$, was used at $0.62 \mathrm{mmol}$ loading over a range of reaction temperatures, from 80 and $130{ }^{\circ} \mathrm{C}(($ blue $=\mathrm{C} 20$, red $=\mathrm{C} 30$, green $=\mathrm{C} 40$, purple $=\mathrm{C} 50$, navy $=\mathrm{C} 60$, orange $=\mathrm{C} 70+$ )

and Figure 3).

Table 5: Product distribution achieved during [BCl $2(2 \mathrm{pic})]\left[\mathrm{Al}_{2} \mathrm{Cl} 7\right]$ catalyzed oligomerization, $0.62 \mathrm{mmol}, 1 \mathrm{~h}$

\begin{tabular}{|c|c|c|c|c|c|c|c|}
\hline $\begin{array}{l}\text { Temp } \\
\left({ }^{\circ} \mathrm{C}\right)\end{array}$ & $\begin{array}{c}\text { Conversion } \\
( \pm 3 \%) \\
\end{array}$ & $\begin{array}{c}C_{20} \\
( \pm 4 \%) \\
\end{array}$ & $\begin{array}{c}\mathrm{C}_{30} \\
( \pm 3 \%) \\
\end{array}$ & $\begin{array}{c}\mathrm{C}_{40} \\
( \pm 2 \%) \\
\end{array}$ & $\begin{array}{c}C_{50} \\
( \pm 2 \%) \\
\end{array}$ & $\begin{array}{c}\mathrm{C}_{60} \\
( \pm 1 \%) \\
\end{array}$ & $\begin{array}{c}\mathrm{C}_{70+} \\
( \pm 1 \%)\end{array}$ \\
\hline 130 & 79 & 39 & 30 & 14 & 9 & 4 & 5 \\
\hline 120 & 77 & 37 & 32 & 15 & 8 & 5 & 3 \\
\hline 110 & 77 & 33 & 32 & 16 & 11 & 5 & 3 \\
\hline 100 & 76 & 31 & 34 & 18 & 9 & 4 & 5 \\
\hline 90 & 80 & 25 & 32 & 18 & 13 & 6 & 6 \\
\hline 80 & 80 & 22 & 31 & 19 & 13 & 8 & 8 \\
\hline
\end{tabular}




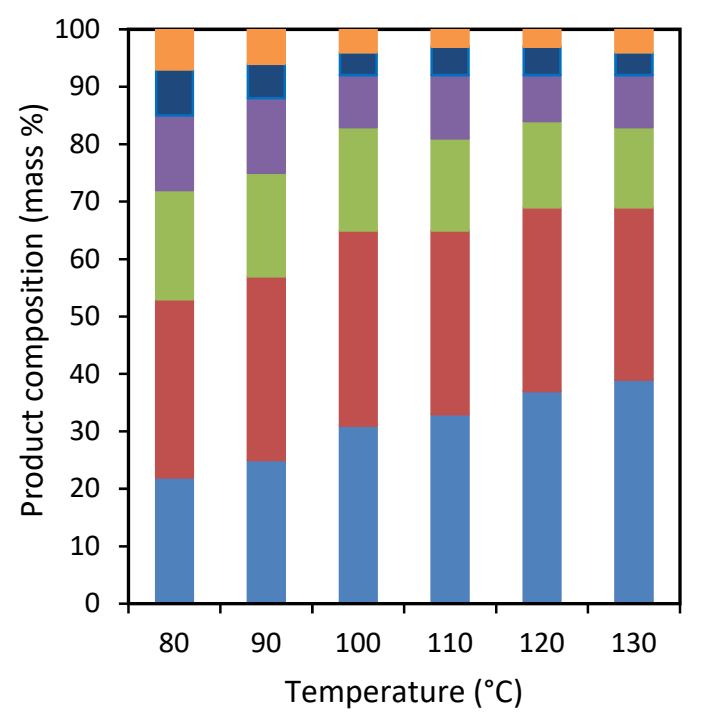

Figure 3: Product distribution from $\left[\mathrm{BCl}_{2}(2 \mathrm{pic})\right]\left[\mathrm{Al}_{2} \mathrm{Cl}_{7}\right]$ catalyzed oligomerization, $0.62 \mathrm{mmol}$ of catalyst, $1 \mathrm{~h}, 100{ }^{\circ} \mathrm{C}$, (blue $=$ $C_{20}$, red $=C_{30}$, green $=C_{40}$, purple $=C_{50}$, navy $=C_{60}$, orange $\left.=C_{70+}\right)$

As expected, less dimer was produced at lower temperatures: its content deceased by $17 \%$, from $39 \%$ at $130{ }^{\circ} \mathrm{C}$ to $22 \%$ at $80{ }^{\circ} \mathrm{C}$. The proportion of $\mathrm{C}_{60+}$ fraction was constant for reaction temperatures of $100{ }^{\circ} \mathrm{C}$ and above, but increased notably for reactions carried out at 80 and $90{ }^{\circ} \mathrm{C}$. From these preliminary results, the temperature of $100{ }^{\circ} \mathrm{C}$ appeared optimal, yielding relatively low proportion of both $\mathrm{C} 20$ (33\%) and heavies (9\%). Nevertheless, within the studied range, conversion appeared independent from the reaction temperature, reaching up to $80 \%$, therefore falling short of the desired $+90 \%$ mark. As such, the catalyst amount was raised from $0.62 \mathrm{mmol}$ to $1.24 \mathrm{mmol}$ to increase conversion. Furthermore, since $\left[\mathrm{BCl}_{2}(2 \mathrm{pic})\right]\left[\mathrm{Al}_{2} \mathrm{Cl}_{7}\right]$ was found to give the lowest conversions among ionic liquids that were screened here (Table 4), two other systems: $\left[\mathrm{BCl}_{2}(4 \mathrm{pic})\right]\left[\mathrm{Al}_{2} \mathrm{Cl}_{7}\right]$ and $\left[\mathrm{BCl}_{2}(\mathrm{py})\right]\left[\mathrm{Al}_{2} \mathrm{Cl}_{7}\right]$, were used in further experiments. The studied temperature range was shifted slightly towards lower temperatures, $60-120{ }^{\circ} \mathrm{C}$ for $\left[\mathrm{BCl}_{2}(\mathrm{py})\right]\left[\mathrm{Al}_{2} \mathrm{Cl}_{7}\right]$, and further reduced to $60-100{ }^{\circ} \mathrm{C}$ for $\left[\mathrm{BCl}_{2}(4 \mathrm{pic})\right]\left[\mathrm{Al}_{2} \mathrm{Cl}_{7}\right]$, focusing on the range that gave low $\mathrm{C}_{20}$ proportion and high conversion (Figure 4 and Table 6). 

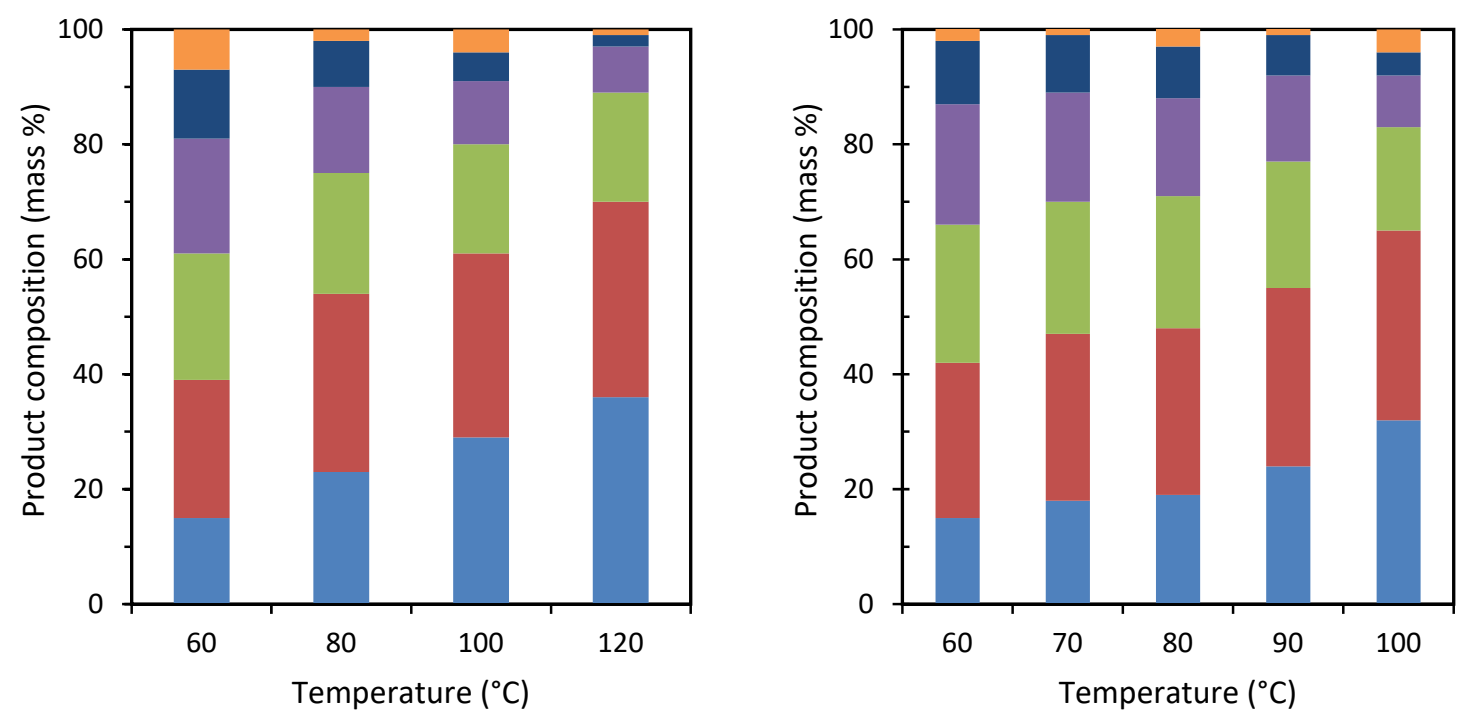

Figure 4: Product distribution from $\left[\mathrm{BCl}_{2}(\mathrm{~L})\right]\left[\mathrm{Al}_{2} \mathrm{Cl}_{7}\right]$ catalyzed oligomerization, $1.24 \mathrm{mmol}$ of catalyst, $1 \mathrm{~h}, 100{ }^{\circ} \mathrm{C},\left(\mathrm{blue}=\mathrm{C}_{20}\right.$, red $=C_{30}$, green $=C_{40}$, purple $=C_{50}$, navy $=C_{60}$, orange $\left.=C_{70+}\right) . L=p y($ left $)$ and 4 pic $($ right $)$.

Table 6: Conversions and product distributions achieved in $\left[\mathrm{BCl}_{2}(\mathrm{~L})\right]\left[\mathrm{Al}_{2} \mathrm{Cl}_{7}\right]$ catalyzed oligomerization, where $L=$ py or 4 pic, $1.24 \mathrm{mmol}, 1 \mathrm{~h}, 100^{\circ} \mathrm{C}$

\begin{tabular}{|c|c|c|c|c|c|c|c|}
\hline $\begin{array}{l}\text { Temp } \\
\left({ }^{\circ} \mathrm{C}\right) \\
\end{array}$ & $\begin{array}{c}\text { Conversion } \\
( \pm 3 \%) \\
\end{array}$ & $\begin{array}{c}\mathrm{C}_{20} \\
( \pm 4 \%) \\
\end{array}$ & $\begin{array}{c}C_{30} \\
( \pm 3 \%) \\
\end{array}$ & $\begin{array}{c}C_{40} \\
( \pm 2 \%) \\
\end{array}$ & $\begin{array}{c}C_{50} \\
( \pm 2 \%) \\
\end{array}$ & $\begin{array}{c}\mathrm{C}_{60} \\
( \pm 1 \%)\end{array}$ & $\begin{array}{c}\mathrm{C}_{70+} \\
( \pm \mathbf{1 \%})\end{array}$ \\
\hline \multicolumn{8}{|c|}{$L=p y$} \\
\hline 120 & 86 & 36 & 34 & 19 & 8 & 2 & 1 \\
\hline 100 & 85 & 29 & 32 & 19 & 11 & 5 & 4 \\
\hline 80 & 85 & 23 & 30 & 21 & 15 & 8 & 2 \\
\hline 60 & 94 & 15 & 23 & 22 & 20 & 12 & 7 \\
\hline \multicolumn{8}{|c|}{$L=4$ pic } \\
\hline 100 & 86 & 32 & 33 & 18 & 9 & 4 & 4 \\
\hline 90 & 88 & 24 & 31 & 22 & 15 & 7 & 2 \\
\hline 80 & 89 & 19 & 29 & 23 & 17 & 9 & 4 \\
\hline 70 & 95 & 18 & 29 & 23 & 19 & 10 & 2 \\
\hline 60 & 96 & 15 & 27 & 24 & 21 & 11 & 3 \\
\hline
\end{tabular}

Increase in catalyst loading gave higher conversion, which increased up to $95 \%$ at lower reaction temperatures $\left(60\right.$ and $\left.70{ }^{\circ} \mathrm{C}\right)$, for both $\left[\mathrm{BCl}_{2}(\mathrm{py})\right]\left[\mathrm{Al}_{2} \mathrm{Cl}_{7}\right]$ and $\left[\mathrm{BCl}_{2}(4 \mathrm{pic})\right]\left[\mathrm{Al}_{2} \mathrm{Cl}_{7}\right]$ (Table 6). At the same time, there was no noticeable change in products distribution: for example, reactions at $100{ }^{\circ} \mathrm{C}$, irrespective of the catalyst used or its loading, yielded $29-32 \%$ of $\mathrm{C}_{20}$ and $8-9 \%$ of the $\mathrm{C}_{60+}$ fraction (viz. relevant data in (blue $=\mathrm{C} 20$, red $=\mathrm{C} 30$, green $=\mathrm{C} 40$, purple $=\mathrm{C} 50$, navy $=\mathrm{C} 60$, orange $=\mathrm{C} 70+$ ) 
and Table 6). As such, increasing the catalyst loading and manipulating the reaction temperature offered a promising strategy.

Less dimer and more heavy oligomers were produced with decreasing temperature, as expected (Figure 4). For $\left[\mathrm{BCl}_{2}(\mathrm{py})\right]\left[\mathrm{Al}_{2} \mathrm{Cl}_{7}\right]$, there was a significant drop in $\mathrm{C}_{20}$ content with decreasing temperature, from $36 \%$ at $120{ }^{\circ} \mathrm{C}$ to $15 \%$ at $60{ }^{\circ} \mathrm{C}$, but offset by increase in the heavy fraction, from only $3 \%$ at $120{ }^{\circ} \mathrm{C}$ to as high as $19 \%$ at $60{ }^{\circ} \mathrm{C}$. Similar results were achieved with $\left[\mathrm{BCl}_{2}(4\right.$ pic) $\left.)\right]\left[\mathrm{Al}_{2} \mathrm{Cl}_{7}\right]$, also reaching $15 \%$ of $\mathrm{C} 20$ at $60{ }^{\circ} \mathrm{C}$, but with only $14 \%$ of the $\mathrm{C}_{60+}$ fraction generated at that temperature. These results were found to be promising enough to motivate largerscale lab tests, producing oligomers in a $5 \mathrm{~L}$ batch reactor. This quantity of sample is suitable for fractionated distillation and subsequent blending to achieve proportion of oligomers that have the potential of meeting market specification: in this work, the targets were PAO4 and 6 .

\section{Large-scale oligomerization of 1-decene}

Screening reactions as a function of catalyst and reaction temperature. Scaled up reactions were performed in a $5 \mathrm{~L}$ batch HEL reactor, with a jacketed glass vessel, a Teflon-coated overhead stirrer and a refrigerated/heating circulator Julabo FP35. The amount of feedstock was increased to $3 \mathrm{~L}$, rendering the effects of thermal runaway potentially much more dangerous. As such, the first reactions were performed with $0.25 \mathrm{wt} \%$ of catalyst (which was a quarter of the $\mathrm{wt} \%$ used for the small-scale reactions). Furthermore, the catalyst was added drop-wise using a syringe pump. As expected, this reduced catalyst loading resulted in conversion drop to $<70 \%$ (representative data sets are listed in Table 7). Once safe pace of addition was established, the catalyst loading was increased to $1.25 \mathrm{wt} \%$, which brought the conversion back up to $c a .85 \%$. 
Table 7: Conversions and product distributions achieved in $[\mathrm{BCl}(\mathrm{L})]\left[\mathrm{Al}_{2} \mathrm{Cl}_{7}\right]$ catalyzed oligomerization, $1 \mathrm{~h}$

\begin{tabular}{|c|c|c|c|c|c|c|c|c|c|}
\hline Catalyst & $\begin{array}{c}\text { Temp. } \\
\left({ }^{\circ} \mathrm{C}\right)\end{array}$ & $\begin{array}{c}\text { Loading } \\
\text { (wt \%) }\end{array}$ & $\begin{array}{c}\text { Convers. } \\
( \pm 3 \%) \\
\end{array}$ & $\begin{array}{c}C_{20} \\
( \pm 4 \%) \\
\end{array}$ & $\begin{array}{c}C_{30} \\
( \pm 3 \%) \\
\end{array}$ & $\begin{array}{c}C_{40} \\
( \pm 2 \%) \\
\end{array}$ & $\begin{array}{c}C_{50} \\
( \pm 2 \%) \\
\end{array}$ & $\begin{array}{c}C_{60} \\
( \pm 1 \%) \\
\end{array}$ & $\begin{array}{c}\mathrm{C}_{70+} \\
( \pm 1 \%) \\
\end{array}$ \\
\hline$\left[\mathrm{BCl}_{2}(4 \mathrm{pic})\right]\left[\mathrm{Al}_{2} \mathrm{Cl}_{7}\right]$ & 100 & 0.25 & 69 & 51 & 32 & 13 & 3 & 2 & 0 \\
\hline$\left[\mathrm{BCl}_{2}(2 \mathrm{pic})\right]\left[\mathrm{Al}_{2} \mathrm{Cl}_{7}\right]$ & 100 & 0.25 & 66 & 50 & 31 & 12 & 3 & 2 & 2 \\
\hline$\left[\mathrm{BCl}_{2}(2 \mathrm{pic})\right]\left[\mathrm{Al}_{2} \mathrm{Cl}_{7}\right]$ & 100 & 0.25 & 69 & 51 & 32 & 13 & 3 & 2 & 0 \\
\hline$\left[\mathrm{BCl}_{2}(\mathrm{py})\right]\left[\mathrm{Al}_{2} \mathrm{Cl}_{7}\right]$ & 100 & 1.25 & 83 & 40 & 36 & 18 & 6 & 0 & 0 \\
\hline$\left[\mathrm{BCl}_{2}(\mathrm{py})\right]\left[\mathrm{Al}_{2} \mathrm{Cl}_{7}\right]$ & 80 & 1.25 & 86 & 34 & 33 & 19 & 10 & 3 & 1 \\
\hline$\left[\mathrm{BCl}_{2}(4 \mathrm{pic})\right]\left[\mathrm{Al}_{2} \mathrm{Cl} \mathrm{l}_{7}\right]$ & 80 & 1.25 & 86 & 34 & 28 & 17 & 10 & 5 & 6 \\
\hline$\left[\mathbf{B C l}_{2}(\mathbf{p y})\right]\left[\mathbf{A l}_{2} \mathbf{C l}_{7}\right]$ & 60 & 1.25 & 86 & 22 & 33 & 22 & 16 & 6 & 1 \\
\hline
\end{tabular}

In general, large-scale reactions gave fewer heavy oligomers than small-scale experiments carried out at the same temperature. It is known that branching and products distribution are sensitive to the amount of adventitious water (as the proton source) that is present in the system, and increase in reactor size will reduce proportion of adventitious water in the system, which may be the source of improved product distribution in this case. In contrast to small-scale experiments, large-scale screening at $80{ }^{\circ} \mathrm{C}$ gave improved selectivity for $\left[\mathrm{BCl}_{2}(\mathrm{py})\right]\left[\mathrm{Al}_{2} \mathrm{Cl} \mathrm{l}_{7}\right]$, when compared to $\left[\mathrm{BCl}_{2}(4 \mathrm{pic})\right]\left[\mathrm{Al}_{2} \mathrm{Cl}_{7}\right]$, both generating the same conversion and $\mathrm{C}_{20}$ loading, but the former producing more heavy oligomers. Reactions with $\left[\mathrm{BCl}_{2}(\mathrm{py})\right]\left[\mathrm{Al}_{2} \mathrm{Cl}_{7}\right]$ were then carried out at 60 and $100{ }^{\circ} \mathrm{C}$, confirming that it yields consistently low heavy fraction.

Potential for catalyst recycling. Throughout this work, after given reaction time the reaction mixtures were quenched with water, which resulted in hydrolysis of the catalyst. The quenching procedure is used in most industrial $\mathrm{PAO}$ plants, using $\mathrm{BF}_{3}$ catalyst. However, in certain refinery alkylation processes (IONIKYLATION, ISOALKY), where Lewis acidic ionic liquids have been piloted and are about to be used commercially, they are being purified and recycled, rather than hydrolysed. ${ }^{15}$ This offers hope for borenium ionic liquids used in this work to be potentially recycled in a cost-efficient manner; however, such purification and recycling process requires a separate study, which is outside of the scope of this work. 
Preparation of base oil samples. Prior to distillation of the large-scale samples, reaction mixtures were dried using magnesium sulfate. Base oil samples were produced by the removal of the decene and then of $\mathrm{C}_{20}$ by distillation under reduced pressure, and subsequent distillation of $\mathrm{C}_{30}$ and $\mathrm{C}_{30}-$ $\mathrm{C}_{40}$ fractions, leaving $\mathrm{C}_{50+}$ residue. These were blended to give samples of PAO4 and PAO6, following proportions suggested by commercial Group 4 base oils, such as Durasyn PAOs manufactured by INEOS in a commercial $\mathrm{BF}_{3}$-catalysed process, which were used as a benchmark in this work.

Key physical properties tested for blended samples were: kinematic viscosity at 40 and $100{ }^{\circ} \mathrm{C}$ $\left(\mathrm{Kv}_{40}\right.$ and $\left.\mathrm{Kv}_{100}\right)$, which were used to derive viscosity index (VI) and pour point (PP). To match market specification, PP must be below $-40{ }^{\circ} \mathrm{C}$, and preferably $<-60{ }^{\circ} \mathrm{C}$. VI must be at least 120 , and as high as possible. Finally, the values of Kv100 must closely match $4 \mathrm{cSt}$ for PAO4 and $6 \mathrm{cSt}$ for PAO6. It is also important for samples to be colourless; any color is typically removed along with double bond presence through hydrogenation. Since there is a small risk of worsening PP during hydrogenation, it is important to test representative PAOs after hydrogenation, to assess any changes in physical properties.

The first rather surprising finding was that, in large-scale experiments, PAOs produced using $\left[\mathrm{BCl}_{2}(\right.$ py) $]\left[\mathrm{Al}_{2} \mathrm{Cl}_{7}\right]$ precipitated a fine white powder after $>24 \mathrm{~h}$. The product, identified as boric acid, was possible to remove by repeated high-temperature water washing, but not by filtration. Furthermore, these PAOs were found to have exceptionally low VIs, consistently below 100 units. In consequence, these PAOs have not been tested for further physical properties.

Representative results for several blends of $\mathrm{PAO} 4$ and 6, produced using $\left[\mathrm{BCl}_{2}(2 \mathrm{pic})\right]\left[\mathrm{Al}_{2} \mathrm{Cl}_{7}\right]$ and $\left[\mathrm{BCl}_{2}(4 \mathrm{pic})\right]\left[\mathrm{Al}_{2} \mathrm{Cl}_{7}\right]$, are listed in Table 8 , and compared to benchmark products. These two 
catalysts yielded VI>120 and low pour points $\left(-57^{\circ} \mathrm{C}\right.$ for the hydrogenated samples), matching commercial requirements.

Table 8: Composition and physical properties of PAO samples produced using borenium ionic liquids, LCCs and compared to commercial PAO samples

\begin{tabular}{|c|c|c|c|c|c|c|c|c|}
\hline Catalyst & $\begin{array}{c}\text { Temperature } \\
\left({ }^{\circ} \mathrm{C}\right)\end{array}$ & $\begin{array}{c}\text { KV100 } \\
\text { (cSt) }\end{array}$ & $\begin{array}{c}\text { KV40 } \\
\text { (cSt) }\end{array}$ & VI & PP $\left({ }^{\circ} \mathrm{C}\right)$ & $\mathrm{C}_{30}(\%)$ & $\mathrm{C}_{40}(\%)$ & $\begin{array}{l}\mathrm{C}_{50+} \\
(\%)\end{array}$ \\
\hline \multicolumn{9}{|l|}{ PAO6 blends } \\
\hline$\left[\mathrm{BCl}_{2}(2 \mathrm{pic})\right]\left[\mathrm{Al}_{2} \mathrm{Cl}_{7}\right]$ & 100 & 6.18 & 33.35 & 136 & $<-60$ & 39 & 36 & 25 \\
\hline$\left[\mathrm{BCl}_{2}(2 \mathrm{pic})\right]\left[\mathrm{Al}_{2} \mathrm{Cl}_{7}\right]^{a}$ & 100 & 6.45 & 35.30 & 137 & -57 & 39 & 36 & 25 \\
\hline$\left[\mathrm{BCl}_{2}(4 \mathrm{pic})\right]\left[\mathrm{Al}_{2} \mathrm{Cl}_{7}\right]$ & 80 & 5.88 & 32.40 & 127 & $<-60$ & 37 & 39 & 24 \\
\hline$\left[\mathrm{BCl}_{2}(4 \mathrm{pic})\right]\left[\mathrm{Al}_{2} \mathrm{Cl}_{7}\right]^{a}$ & 80 & 6.22 & 35.50 & 122 & -57 & 37 & 39 & 24 \\
\hline $\mathrm{Ur}-\mathrm{AlCl}_{3}\left(\chi_{A I C l 3}=\mathbf{0 . 6 0}\right)^{21}$ & 120 & 5.79 & 31.46 & 126 & $<-60$ & 42 & 63 & 22 \\
\hline Durasyn PAO6 & - & 5.76 & 30.22 & 135 & -57 & 37 & 42 & 21 \\
\hline \multicolumn{9}{|l|}{ PAO4 blends } \\
\hline$\left[\mathrm{BCl}_{2}(2 \mathrm{pic})\right]\left[\mathrm{Al}_{2} \mathrm{Cl}_{7}\right]$ & 100 & 4.23 & 18.87 & 132 & $<-60$ & 80 & 14 & 6 \\
\hline$\left[\mathrm{BCl}_{2}(4 \mathrm{pic})\right]\left[\mathrm{Al}_{2} \mathrm{Cl}_{7}\right]$ & 80 & 3.95 & 17.34 & 125 & $<-60$ & 76 & 15 & 9 \\
\hline Durasyn PAO 4 & - & 3.92 & 17.25 & 137 & $<-60$ & 80 & 19 & 1 \\
\hline $\mathrm{Ur}-\mathrm{AlCl}_{3}\left(\chi_{\mathrm{AICl} 3}=0.60\right)^{21}$ & 100 & 4.31 & 20.08 & 124 & $<-60$ & 77 & 16 & 7 \\
\hline
\end{tabular}

${ }^{a}$ Samples after hydrogenation

Branching. In order to understand the performance differences between borenium ionic liquids bearing pyridine or picoline ligands, a quick method to compare the degree of branching was used. VI is related to degrees of chain branching, and chain branching originates from double bond migration/isomerization. The degree of branching can be approximated from ${ }^{1} \mathrm{H}$ NMR spectroscopy, because linear alpha olefins have distinctive spectra with two multiplets at $c a .5 .8$ and $4.9 \mathrm{ppm}$, in a 1:2 ratio, whereas internal olefins have a multiplet at $c a .5 .4 \mathrm{ppm}$. Thus, the degree of isomerization can be approximated by the 5.8 to $5.4 \mathrm{ppm}$ signal ratio. The largest percentage of double bonds to the alkyl chain was expected in decene fraction, recovered after the oligomerization process. ${ }^{1} \mathrm{H}$ NMR spectra of decene fractions recovered post-oligomerization, carried out with different catalysts, at different loadings and temperatures, are shown in Table 9.

Table 9. Ratio of isomerized to linear decene present in decene fraction recovered from selected post-reaction mixtures, using a range of borenium catalysts, at various loadings and temperatures.

\begin{tabular}{lcccc}
\hline Catalyst & $\begin{array}{c}\text { Catalyst } \\
(\mathbf{w t} \%)\end{array}$ & $\begin{array}{c}\text { Temperature of } \\
\text { reaction }\left({ }^{\circ} \mathbf{C}\right)\end{array}$ & $\begin{array}{c}\text { Conversion } \\
(\%)\end{array}$ & $\begin{array}{c}\text { 5.8ppm : 5.4ppm } \\
\text { Peak Ratio }\end{array}$ \\
\hline Feedstock (virgin) & - & - & - & $33: 1$ \\
{$\left[\mathbf{B C l}_{2}(2 \mathrm{pic})\right]\left[\mathbf{A l}_{2} \mathbf{C l}_{7}\right]$} & 1 & 100 & 79 & $1: 21$ \\
{$\left[\mathbf{B C l}_{2}(4\right.$ pic)$]\left[\mathrm{Al}_{2} \mathbf{C l}_{7}\right]$} & 1 & 100 & 86 & $1: 6$ \\
\hline
\end{tabular}




\begin{tabular}{lcccc}
\hline$\left[\mathbf{B C l}_{2}(\mathbf{p y})\right]\left[\mathbf{A l}_{2} \mathbf{C l}_{7}\right]$ & 1 & 100 & 85 & $1: 95$ \\
{$\left[\mathbf{B C l}_{2}(\mathbf{p y})\right]\left[\mathbf{A l}_{\mathbf{2}} \mathbf{C l}_{7}\right]$} & 2 & 80 & 85 & $1: 84$ \\
{$\left[\mathbf{B C l}_{2}(\mathbf{p y})\right]\left[\mathbf{A l}_{\mathbf{2}} \mathbf{C l}_{7}\right]$} & 2 & 60 & 96 & $1: 33$ \\
\hline
\end{tabular}

In all post-reaction decene fractions, there was a significant degree of double bond isomerization, but the result was largely dependent on both the catalyst and the reaction temperature. Using $\left[\mathrm{BCl}_{2}(\mathrm{py})\right]\left[\mathrm{Al}_{2} \mathrm{Cl}_{7}\right]$ resulted in a much higher degree of double bond isomerization in the residual decene, compared to the other two catalysts, and lower temperature aided to decrease branching. It is apparent that relatively small modification to the $\mathrm{N}$-donor ligand, that is the presence and position of the methyl substituent, have quite significant influence on the physical properties of the products. It is unclear at this stage why using pyridine results in high branching and in the presence of boric acid in the product, and why using 4pic gives significantly lower branching than either of the other ligands. Elucidating this will require in-depth mechanistic studies, combining in operando spectroscopic techniques and computer modeling. However, these results bear promise of impressive tuneability of the product properties by altering the reaction temperature and the ligand on the borenium cation.

The same samples were also studied using ${ }^{11} \mathrm{~B}$ and ${ }^{13} \mathrm{C}$ NMR spectroscopy. Whereas ${ }^{13} \mathrm{C}$ spectra offered no additional insight into structural differences between PAO samples, it has been impossible to detect any ${ }^{11} \mathrm{~B}$ signals, suggesting that boron has not been incorporated in the PAO product (at least not within the detection limit of ${ }^{11} \mathrm{~B}$ NMR spectroscopy).

\section{Conclusions}

Through this work, we demonstrate the potential of non-volatile, fluoride-free borenium ionic liquid to replace $\mathrm{BF}_{3}$ (toxic and corrosive gas), as a safer catalyst for PAO syntheses, capable of delivering the same yield and quality of low-viscosity lubricant base oil grades (PAO4 and 6). 
Borenium ionic liquids of the general formula $\left[\mathrm{BCl}_{2}(\mathrm{~L})\right]\left[\mathrm{M}_{2} \mathrm{Cl}_{7}\right](\mathrm{M}=\mathrm{Ga}, \mathrm{Al})$, were shown to be effective 1-decene oligomerization catalysts, and a possible alternative to $\mathrm{BF}_{3} / n \mathrm{BuOH}$ catalyzed 1-decene oligomerization. They were successfully employed on a $3 \mathrm{~L}$ scale to produce 1-decene oligomers which, were fractionated and blended to give PAO 4 and PAO 6 matching commercial specifications. Increase in reaction scale from $40 \mathrm{~mL}$ to $3 \mathrm{~L}$ had significant effect on product distribution and properties, which was expected for carbocationic oligomerization. Hydrogenation of selected blended PAO6 samples was shown to slightly increase the viscosity and the pour point, but all parameters remained within specifications, and these changes could be taken into consideration in future blending exercises. Temperature and ligand choice had large influence on the quality of PAOs; methypyridines produced samples with VI $>120$, but pyridine did not, which was apparent only from large-scale experiments. This opens up the potential for further optimization, based on modifying ligands on the boron center. Considering complicated mechanism of carbocationic oligomerisation, in-depth understanding on the relationship between the ligand and the reaction outcome calls for a separate mechanistic study. Finally, since all components of borenium ionic liquids are inexpensive, off-the-shelf reactants, and the catalyst can be synthesized through a one-pot process, it presents itself as an economically-viable alternative to $\mathrm{BF}_{3}$. Furthermore, very significant CAPEX (capital expenditure) savings are expected from switching from toxic gas to an ionic liquid, in analogy to the ISOALKY process by Chevron, where HF was replaced by a Lewis acidic ionic liquid. ${ }^{15}$

\section{Acknowledgements}

The QUILL Research Centre and Evonik Industries are acknowledged for funding this project.

\section{Supporting Information}


Detailed synthetic procedure for borenium ionic liquids, ${ }^{1} \mathrm{H}$ and ${ }^{11} \mathrm{~B}$ NMR spectra of the products

\section{References}

(1) Torbacke, M.; Rudolphi, Å. K. Å.; Kassfeldt, E. Lubricants: Introduction to Properties and Performance; Torbacke, M., Rudolphi, Å. K., Kassfeldt, E., Eds.; John Wiley \& Sons Ltd: Chichester, UK, 2014. https://doi.org/10.1002/9781118799734.

(2) Benda, R.; Bullen, J.; Plomer, A. Polyalphaolefin - Base Fluids for High Perfomance Lubricants. J. Synth. Lubr. 1996, 13 (1), 44-57.

(3) Kirk-Othmer Encyclopedia of Chemical Technology; John Wiley \& Sons Inc, Ed.; John Wiley \& Sons, Inc.: Hoboken, NJ, USA, 2000. https://doi.org/10.1002/0471238961.

(4) Rudnick, L. Synthetics, Mineral Oils, and Bio-Based Lubricants: Chemistry and Technology; Rudnick, L., Ed.; CRC Press: Boca Raton, 2006.

(5) Kioupis, L. I.; Maginn, E. J. Molecular Simulation of Poly- $\alpha$-Olefin Synthetic Lubricants: Impact of Molecular Architecture on Performance Properties. J. Phys. Chem. B 1999, 103, 10781-10790.

(6) Scheuermann, S. S.; Eibl, S.; Bartl, P. Detailed Characterisation of Isomers Present in Polyalphaolefin Dimer and the Effect of Isomeric Distribution on Bulk Properties. Lubr. Sci. 2011, 23 (5), 221-232. https://doi.org/10.1002/ls.151.

(7) Kennedy, J.; Maréchal, E. Carbocationic Polymerization; John Wiley \& Sons Inc: New York, 1982. 
(8) Ray, S.; Rao, P. V. C.; Choudary, N. V. Poly- $\alpha$-Olefin-Based Synthetic Lubricants: A Short Review on Various Synthetic Routes. Lubr. Sci. 2012, 24 (1), 23-44. https://doi.org/10.1002/1s.166.

(9) Brennan, J. Wide-Temperature Range Synthetic Hydrocarbon Fluids. Ind. Eng. Chem. Prod. Res. Dev. 1980, 19, 2-6.

(10) Brennan, J. Polymerization of Olefins with BF3. United States Patent 3382291, 1965.

(11) Kumar, G.; Davis, M. Oligomerization of Alpha-Oelfins. United States Patent 5196635, 1993.

(12) Ohn, N.; Kim, J. G. Studies on Poly A-Olefin Synthesis by AlCl 3 -catalyzed Cationic Polymerization: Concentration Effect on Molecular Weight and Viscosity. Bull. Korean Chem. Soc. 2019, 40 (3), 289-292. https://doi.org/10.1002/bkcs.11678.

(13) Shao, H.; Li, H.; Lin, J.; Jiang, T.; Guo, X.; Li, J. Metallocene-Catalyzed Oligomerizations of 1-Butene and $\alpha$-Olefins: Toward Synthetic Lubricants. Eur. Polym. J. 2014, 59, 208217. https://doi.org/10.1016/j.eurpolymj.2014.08.002.

(14) Marquis, E. T.; Sanderson, J. R. Process for Oligomerizing Olefins to Prepare Base Stocks for Synthetic Lubricants. United States Patent 5053569, 1991.

(15) Brown, L. C.; Hogg, J. M.; Swadźba-Kwaśny, M. Lewis Acidic Ionic Liquids. Top. Curr. Chem. 2017, 375 (5), 78. https://doi.org/10.1007/s41061-017-0166-z.

(16) Ghosh, R.; Bandyopadhyay, A. R.; Jasra, R. Catalytic Oligomerization of Octenes. United States Patent 9546231 B2, 2017. 
(17) Elomari, S.; Krug, R. R. Process to Make Lubricant Component by Oligomerization and Alkylating at a Molar Ratio of Olefin to Isoparaffin of at Least 0.8. United States Patent 7973205 B2, 2011.

(18) Elomari, S.; Krug, R. R.; Miller, S. J. Process to Make Base Oil from Thermally Cracked Waxy Feed Using Ionic Liquid Catalyst. United States Patent 7973204 B2, 2011.

(19) Atkins, M. P.; Seddon, K. R.; Swadźba-Kwaśny, M. Oligomerisation of Linear 1-Olefins Using a Chlorogallate(III) Ionic Liquid. Pure Appl. Chem. 2011, 83 (7), 1391-1406. https://doi.org/10.1351/PAC-CON-10-12-03.

(20) Coleman, F.; Srinivasan, G.; Swadźba-Kwaśny, M. Liquid Coordination Complexes Formed by the Heterolytic Cleavage of Metal Halides. Angew. Chem. Int. Ed. 2013, 52 (48), 12582-12586. https://doi.org/10.1002/anie.201306267.

(21) Hogg, J. M.; Coleman, F.; Ferrer-Ugalde, A.; Atkins, M. P.; Swadźba-Kwaśny, M. Liquid Coordination Complexes: A New Class of Lewis Acids as Safer Alternatives to BF 3 in Synthesis of Polyalphaolefins. Green Chem. 2015, 17, 1831-1841. https://doi.org/10.1039/c4gc02080d.

(22) Coffie, S.; Hogg, J. M.; Cailler, L.; Ferrer-Ugalde, A.; Murphy, R. W.; Holbrey, J. D.; Coleman, F.; Swadźba-Kwaśny, M. Lewis Superacidic Ionic Liquids with Tricoordinate Borenium Cations. Angew. Chem. Int. Ed. 2015, 54, 14970-14973. https://doi.org/10.1002/anie.201508653.

(23) Clark, E. R.; Del Grosso, A.; Ingleson, M. J. The Hydride-Ion Affinity of Borenium Cations and Their Propensity to Activate H2 in Frustrated Lewis Pairs. Chemistry 2013, 19 (7), 
2462-2466. https://doi.org/10.1002/chem.201203318.

(24) Clark, E. R.; Ingleson, M. J. [(Acridine)BCl2]+: A Borenium Cation That Is a Strong Boronand Carbon-Based Lewis Acid. Organometallics 2013, 32 (22), 6712-6717. https://doi.org/10.1021/om400463r.

(25) Matuszek, K.; Coffie, S.; Chrobok, A.; Swadźba-Kwaśny, M. Borenium Ionic Liquids as Catalysts for Diels-Alder Reaction: Tuneable Lewis Superacids for Catalytic Applications. Catal. Sci. Technol. 2017, 7 (5), 1045-1049. https://doi.org/10.1039/c7cy00106a.

(26) Robinson, J.; Osteryoung, R. a. Electrochemical and Spectroscopic Study of Some Aromatic-Hydrocarbons in the Room-Temperature Molten-Salt System Aluminum Chloride-N-Butylpyridinium Chloride. J. Am. Chem. Soc. 1979, 101, 323-327. https://doi.org/10.1021/ja00496a008.

(27) ASTM D6352-15, Standard Test Method for Boiling Range Distribution of Petroleum Distillates in Boiling Range from $174{ }^{\circ} \mathrm{C}$ to $700{ }^{\circ} \mathrm{C}$ by Gas Chromatography, ASTM International, West Conshohocken, PA, 2015, www.astm.org. https://doi.org/10.1520/D6352-15.

(28) ASTM D5236-18a, Standard Test Method for Distillation of Heavy Hydrocarbon Mixtures (Vacuum Potstill Method), ASTM International, West Conshohocken, PA, 2018, www.astm.org. https://doi.org/10.1520/D5236-18A.

(29) ASTM D97-17b, Standard Test Method for Pour Point of Petroleum Products, ASTM International, West Conshohocken, PA, 2017, www.astm.org. https://doi.org/10.1520/D0097-17B. 
(30) ASTM D445-19, Standard Test Method for Kinematic Viscosity of Transparent and Opaque Liquids (and Calculation of Dynamic Viscosity), ASTM International, West Conshohocken, PA, 2019, www.astm.org. https://doi.org/10.1520/D0445-19.

(31) ASTM D2270 - 10(2016) Standard Practice for Calculating Viscosity Index from Kinematic Viscosity at $40{ }^{\circ} \mathrm{C}$ and $100{ }^{\circ} \mathrm{C}$, ASTM International, West Conshohocken, PA, 2015, www.astm.org. https://doi.org/10.1520/D2270-10R16.

(32) Ingleson, M. J. Fundamental and Applied Properties of Borocations. Top. Organomet. Chem. 2015, 49, 39-71. https://doi.org/10.1007/978-3-319-13054-5_2.

(33) Xiao, L.; Johnson, K. E.; Treble, R. G. Alkane Cracking, Alkene Polymerization, and Friedel-Crafts Alkylation in Liquids Containing the Acidic Anions HX2-, XH(AlX 4)-, XH(Al2X7)-, and Al2X7- (X = Chlorine, Bromine). J. Mol. Catal. A Chem. 2004, 214 (1), 121-127. https://doi.org/10.1016/j.molcata.2003.12.030.

(34) Welton, T. Room-Temperature Ionic Liquids. Solvents for Synthesis and Catalysis. Chem. Rev. 1999, 99, 2071-2083.

(35) Matuszek, K.; Chrobok, A.; Hogg, J.; Coleman, F.; Swadźba-Kwaśny, M. Friedel-Crafts Alkylation Catalysed by $\mathrm{GaCl}$ 3-Based Liquid Coordination Complexes. Green Chem. 2015, 17, 4255-4262. https://doi.org/10.1039/c5gc00749f.

(36) Coleman, F.; Coffie, S.; Atkins, M. P.; Hogg, J. M.; Ferrer-Ugalde, A.; Swadźba-Kwaśny, M.; Fedor, G. Oligomerisation Process. WO/2016/005769, 2016. 


\section{For Table of Contents Use Only}

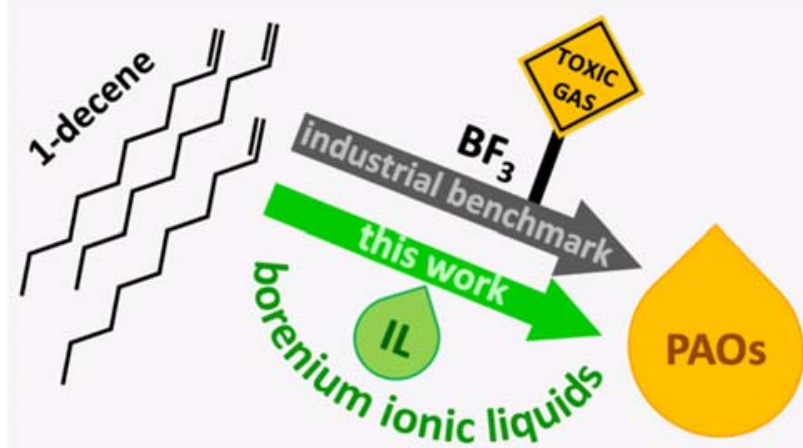

Non-volatile, fluoride-free borenium ionic can replace $\mathrm{BF}_{3}$ (toxic and corrosive gas) as a safer catalyst for the syntheses of low-viscosity polyalphaolefins. 